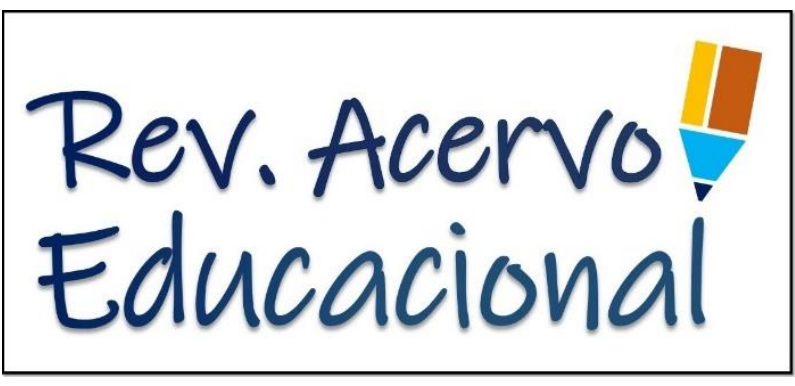

REVISÃO BIBLIOGRÁFICA

Recebido em: 6/2020

Aceito em: $7 / 2020$

Publicado em: 10/2020

\title{
A importância da educação na construção da cidadania: uma análise do Programa Bolsa Família
}

\author{
The importance of education in construction of citizenship: an analysis of the Family \\ Scholarship Program
}

La importancia de la educación en la construcción de la ciudadanía: un análisis del Programa Bolsa Familia

Luiz Claudio de Almeida Teodoro ${ }^{1 *}$.

\begin{abstract}
Resumo: O objetivo deste trabalho é analisar como o Programa Bolsa Família (PFB), através da condicionalidade em educação, pode ser um elemento importante na quebra intergeracional da exclusão educacional e da pobreza, a condicionalidade cumpre um papel estratégico para o desenvolvimento da cidadania no país. Enquanto um pré-requisito para outros direitos, a educação é considerada como um direito genuíno da Cidadania. No entanto, a história da educação no Brasil é marcada pelo elitismo e exclusão. $O$ Estado Brasileiro só irá reconhecer a educação como direito de todos na constituição de 1934. Porém, somente após a constituição de 1988 o país alcançou avanços significativos na área. As políticas de assistência educacional e social são fundamentais para esse avanço, sobretudo na garantia da inclusão dos mais pobres. Desta forma, o PBF, através das condicionalidades, constitui-se em uma relevante estratégia para o rompimento da transmissão intergeracional da pobreza e diminuição da desigualdade no Brasil. Palavras-chave: Educação, Bolsa família, Cidadania.
\end{abstract}

\begin{abstract}
The objective of this work is to analyze how the Bolsa Família Program (PFB), through conditionality in education, can be an important element in the intergenerational break of educational exclusion and poverty, conditionality plays a strategic role for the development of citizenship in the parents. As a prerequisite for other rights, education is considered to be a genuine right of Citizenship. However, the history of education in Brazil is marked by elitism and exclusion. The Brazilian State will only recognize education as a right of all in the 1934 constitution. However, only after the 1988 constitution did the country achieve significant advances in the area. Educational and social assistance policies are fundamental to this progress, especially in ensuring the inclusion of the poorest. Thus, the PBF, through conditionalities, constitutes a relevant strategy for breaking the intergenerational transmission of poverty and reducing inequality in Brazil.
\end{abstract}

Keywords: Education, Family bag, Citizenship.

Resumen: El objetivo de este trabajo es analizar cómo el Programa Bolsa Familia (PFB), a través de la condicionalidad en la educación, puede ser un elemento importante en la ruptura intergeneracional de la

${ }^{1}$ Centro Federal de Educação Tecnológica de Minas Gerais (CEFET MG). Belo Horizonte - MG.

*E-mail: luiz_teodoro@yahoo.com.br 
exclusión educativa y la pobreza, la condicionalidad juega un papel estratégico para el desarrollo de la ciudadanía en el padres Como prerrequisito para otros derechos, la educación se considera un derecho genuino de ciudadanía. Sin embargo, la historia de la educación en Brasil está marcada por el elitismo y la exclusión. El Estado brasileño solo reconocerá la educación como un derecho de todos en la constitución de 1934. Sin embargo, fue solo después de la constitución de 1988 que el país logró avances significativos en el área. Las políticas educativas y de asistencia social son fundamentales para este progreso, especialmente para garantizar la inclusión de los más pobres. Por lo tanto, el PBF, a través de las condicionalidades, constituye una estrategia relevante para romper la transmisión intergeneracional de la pobreza y reducir la desigualdad en Brasil.

Palabras clave: Educación, Bolsa família, Ciudadanía.

\section{INTRODUÇÃO}

Segundo Cury CRJ (1996), o Direito a Educação Escolar é uma garantia constitucional em praticamente todos os países do mundo. O que não significa que o debate sobre o tema seja obsoleto. Ao contrário, questões como o acesso e a qualidade permanecem atuais, tanto no espaço acadêmico, como no cotidiano da vida escolar. Tão pouco se pode negligenciar a importância da Educação escolar enquanto uma dimensão fundante da cidadania.

Portanto, as políticas educacionais e sociais, que buscam corrigir as distorções da desigualdade econômica, sobretudo quanto ao acesso e a permanência de crianças e jovens de famílias pobres na escola, aparecem, hodiernamente, como estratégias fundamentais para a redução da exclusão educacional no Brasil. É o caso do Programa Bolsa Família que, para além do alívio imediato a situação de pobreza da família beneficiária, tem contribuído de forma decisiva na quebra do ciclo intergeracional da pobreza em virtude da vinculação do benefício ao cumprimento de condicionalidades em saúde e educação, principalmente (CURY CRJ, 1996).

Assim, o ponto de partida desse trabalho será a reflexão sobre o direito a educação enquanto um direito genuíno de Cidadania, nos termos postos por Marshall TH (1967). Em seguida, pretendeu-se discorrer sobre o desenvolvimento dos direitos, e consequentemente da cidadania, no Brasil, fazendo o paralelo dos avanços e retrocessos ao direito a educação no país. Por fim, analisou-se a importância e os resultados da condicionalidade em educação do PBF, para a efetiva garantia do direito a educação e seus reflexos para 0 desenvolvimento da cidadania das famílias mais pobres.

Esse artigo tem como objetivo refletir, por meio de uma revisão narrativa, o papel do Programa Bolsa Família na promoção da cidadania, a partir da condicionalidade em Educação, enquanto um elemento importante para o pleno exercício do direito a educação das famílias mais pobres.

\section{REVISÃO BIBLIOGRÁFICA}

\section{Educação como direito genuíno de cidadania}

Segundo Marshall TH (1967), a educação é "um direito social de cidadania genuíno", porque o objetivo da educação durante a infância seria moldar o adulto em perspectiva. Ou seja, o direito a educação ultrapassa a garantia de a criança frequentar a escola e projeta para o direito de o indivíduo adulto ter sido educado, e, consequentemente, se reconhecer e ser reconhecido como cidadão.

Nesse sentido, como afirma Cury CRJ (2002), o acesso à educação é a porta que abre ao indivíduo a possibilidade da formação e, consequentemente, melhores escolhas no mercado de trabalho, além de uma postura mais crítica na sociedade como cidadão. Desta forma, cabe ao Estado garantir a educação escolar, enquanto projeto cívico de formação de cidadãos. Segundo Marshall TH (1967), na medida em que o Estado garante que todos os indivíduos terão acesso à educação, possibilita uma sociedade com uma postura cidadã, consciente de seus direitos e deveres. Assim, busca fomentar o desenvolvimento de cidadãos em formação. 
Marshall TH (1967) justifica assim a necessidade da coerção estatal para garantir a instrução das crianças, pois não se poderia esperar, segundo ele, que as pessoas mais ignorantes e brutalizadas pelo trabalho braçal buscassem livremente pela educação escolar. Portanto, o Estado deve impor as crianças a frequentarem a escola porque 0 analfabeto irá ter grandes dificuldades para se enquadrar no mercado de trabalho, além da limitação de reconhecer seus direitos e deveres como cidadão. (MARSHALL TH, 1967).

Assim, a obrigatoriedade impõe ao Estado o ônus de manter a gratuidade, afinal, não se poderia obrigar as pessoas a frequentarem a escola sem que fosse garantido o acesso. A esse respeito Cury CRJ (2002) afirma que a é fundamental o ensino primário ser um direito dos indivíduos e gratuito, pois é uma estratégia de torná-lo acessível a todos.

Apesar dos desvios e retrocessos não previstos por Marshall TH (1967), o surgimento sequencial sugere que os direitos, e, portanto, a própria cidadania, nasce e se desenvolve por conjunturas históricas dadas. Desta forma, cada país, a partir de sua realidade histórica, traçará um caminho distinto de outros quanto ao desenvolvimento dos direitos, especialmente a educação.

\section{Educação e cidadania no Brasil: um lento caminhar}

No Brasil, o desenvolvimento dos direitos e, assim, da cidadania, no sentido posto por Marshall TH (1967), tem seu marco inicial entre os anos de 1930 e 1943. Esse período é marcado por profundas transformações políticas, sociais e econômicas, mas, sobretudo, pela transformação do papel do Estado no campo dos direitos sociais.

A Constituição Federal de 1934 é pioneira ao definir responsabilidades sociais do Estado, que irão expressar uma nova ordem política e ideológica na relação entre o Estado e a sociedade civil. Assim, a educação aparece, pela primeira vez em um texto constitucional brasileiro, como direito de todos e dever dos Poderes Públicos, determinando vinculação de recursos para seu financiamento, e tornando-o gratuito e obrigatório na rede pública existente e em expansão (CARVALHO JM, 2014).

No período que se segue ao Estado Novo, pouca coisa será alterada quanto às práticas e instituições. Mesmo com as mudanças no capítulo da Ordem Econômica e Social da nova Constituição (1946), que acentua o papel do Estado no desenvolvimento econômico e atribui-lhe a responsabilidade da justiça social, a nova ordem democrática não significou avanços significativos no sistema educacional brasileiro, sobretudo quanto à universalização.

Tanto que, em meados da década de 1960, quando do advento da ditadura militar no Brasil, o índice de analfabetismo no país era de $46 \%$ da população, enquanto que a taxa de escolarização atingia somente $66 \%$ do segmento etário de 7 a 14 anos (POCHMANN M, 2016).

Assim, o Brasil chega à década de 1980 com um sistema de proteção extremamente limitado e incapaz de responder, não só as novas questões que passam a ser colocadas, como a generalização da pobreza, mas, sobretudo, aquelas antigas questões sobre a universalização do sistema em áreas sociais básicas, como saúde, habitação e educação (CARVALHO JM, 2014).

No entanto, o aprofundamento da crise econômica e social nos anos finais da ditadura militar elevou para o debate político o resgate da "dívida social" como uma bandeira política legitimadora pela redemocratização. Ou seja, não bastava mais apenas a liberdade política e a garantia dos direitos civis, mas também a garantia dos direitos sociais (SILVA MOS, et al., 2006).

Nessa perspectiva, os "novos movimentos sociais", que eclodem a partir da reorganização do movimento sindical, do reordenamento dos partidos políticos, e a forte atuação da Igreja Católica, nos finais dos anos 70, tinham como elemento mobilizador, segundo Silva MOS, et al. (2006), novos apelos sociais para o resgaste do ônus social produzido e piorado pelos governos militares e, consequentemente, pela ampliação de direitos sociais, num movimento de ampliação da cidadania.

Nesse sentido, a Constituição de 1988 eleva a obrigatoriedade dos gastos com ensino, tendo a União passado de $10 \%$ para $18 \%$ das despesas, e estados e municípios de $20 \%$ para $25 \%$. Além disto, a criação 
do Fundo de Manutenção e Desenvolvimento do Ensino Fundamental e de Valorização do Magistério (FUNDEF), em 1996 (Lei oㅡ 9.424/96), possibilitou ainda a disciplinarização dos recursos destinados nas três esferas federadas. De modo que, como aponta Cury CRJ (2002), o poder público municipal teve que investir na educação fundamental, pois senão perderiam repasses de recurso do Governo Federal.

As mudanças nos critérios de financiamento da educação irão garantir resultados significativos na área, possibilitando, tanto a quase universalização do ensino fundamental, cuja taxa de escolarização líquida do segmento etário de 7 a 14 anos passou de 80,1\%, em 1980, para 99\%, em 2016, quanto o aumento considerável na taxa de escolarização no ensino médio, passando de 14,3\%, em 1980, para 52,2\%, em 2016 (INEP, 2017).

Apesar da taxa de escolarização no ensino superior no Brasil ainda ser baixa, apenas 14,4\% (INEP, 2016), o apoio governamental, através de iniciativas como o Programa Universidade para Todos (ProUni), o Programa de Financiamento Estudantil (Fies), o Programa de Apoio a Planos de Reestruturação e Expansão das Universidades Federais (Reuni), exerceu um papel expressivo para o avanço recente. Assim como o aumento da oferta de cursos superiores a distância e as políticas de cotas têm possibilitado a ampliação, mesmo que limitada, do número de estudantes oriundos das classes populares nas universidades.

Contudo, mesmo com essa significativa melhora no período, esse quadro ainda está longe do desejável, uma vez que menos da metade dos jovens de 16 anos, dentre as famílias em situação de pobreza, conseguem terminar o ensino fundamental. Assim, se o Brasil praticamente conseguiu universalizar o acesso das crianças nessa etapa do ensino, a universalização da conclusão ainda é um desafio distante, sobretudo entre os mais pobres, mantendo ainda os traços históricos da exclusão educacional do país.

\section{A educação no Programa Bolsa Família: do alívio a pobreza ao direito à educação}

A ampliação do sentido da Gratuidade da educação, expressa na constituição de 1988 e a nova Lei de Diretrizes Básicas da Educação Nacional (LDB), tem um papel fundamental nos avanços educacionais dos últimos anos no Brasil. Nesse sentido, como forma de garantir a igualdade de acesso e, especialmente, permanência no ensino (BRASIL, 1996), cabe ao Estado garantir assistência ao aluno durante todo seu processo educativo.

Conforme nos aponta Melchior JCA (2011), a gratuidade pode ser dividida em dois elementos essenciais: passiva, referente a não cobrança de mensalidades escolares, ou seja, a garantia da matrícula, propriamente dita; e ativa, que se ajusta às diferentes condições socioeconômicas dos alunos e requer, consequentemente, escolas sem mensalidades e assistência ao educando durante o desenvolvimento do processo educativo. Portanto refere-se aos investimentos que possibilitam que a criança não só acesse, mas frequente a escola e siga seus estudos.

A garantia da alimentação e do transporte escolar, de material didático, uniforme, ou mesmo a assistência médica, oftalmológica, dentária e hospitalar, são exemplos da gratuidade ativa citada por Melchior JCA (2011).

Porém, é importante destacar ainda o papel das políticas de inclusão educacional e social implementadas nos últimos anos, em especial a gestão das condicionalidades de educação do Programa Bolsa Família (PBF), que pode ser apontada como outro aspecto da gratuidade ativa e constitui-se como elemento central da evolução da conclusão do segmento mais pobre dentre os jovens de 16 anos.

Nesse sentido, as condicionalidades configuram-se no eixo estruturante do Programa, uma vez que impõe às famílias beneficiadas uma série de compromissos que, caso não sejam cumpridos, pode levar a suspensão, bloqueio ou cancelamento do benefício. Desta forma, ao serem inseridas no programa, as famílias se comprometem a cumprir as condicionalidades do Bolsa Família nas áreas de saúde e educação, principalmente.

Em um primeiro momento, as condicionalidades podem ser vistas como um instrumento para legitimar o benefício pago pelo governo. Com as condicionalidades, conforme salienta Schwarzman S (2009), o Programa não estaria inserido numa lógica assistencialista de mera transferência de renda, se caracterizando como uma simples esmola dada pelo Governo. 
No entanto, o objetivo principal do cumprimento das condicionalidades, segundo as definições do programa, é garantir o acesso da população mais pobre aos direitos sociais básicos como educação e saúde, tendo em vista os resultados que esses podem ter quanto ao rompimento do ciclo de pobreza que é perpetuado de uma geração a outra (MDS, 2018).

Essa avaliação se baseia no fato de que a família pobre, sendo mais vulnerável a riscos (desemprego, fome, geológicos em virtude do tipo de moradia, etc.), e tendo menos condições de enfrentá-los, normalmente lançam mão da educação ou do cuidado da saúde dos filhos para que esses possam ajudar na renda da casa. Sacrificando, dessa forma, o futuro das crianças e da própria família com o passar dos anos.

A esse respeito Arbix G (2007) salienta que para os excluídos socialmente ações de curto prazo, que tenham apenas impactos imediatos, podem implicar em consequências muitas mais desastrosas à médio $\mathrm{e}$ longo prazos, piorando muito a situação de origem.

Como afirmado anteriormente, de acordo com a Constituição de 1988 e a nova LDB (1996), a obrigatoriedade da educação escolar impõe ao Estado o ônus de manter a gratuidade. No entanto, essa gratuidade não se configura apenas ao acesso, mas, sobretudo para a população mais pobre, na garantia da permanência na escola.

Portanto, a condicionalidade em educação cumpre um papel que vai além da mera contrapartida do beneficiário pelo valor recebido, mas na garantia da correção de certas desigualdades que tem implicações diretas nas condições futuras de vida do aluno das famílias beneficiárias. Podendo, inclusive, ser considerada outro aspecto da gratuidade ativa, no sentido posto por Melchior JCA (2011), na medida em que condiciona o benefício recebido pela família a frequência e permanência da criança na escola.

Sobre os resultados da condicionalidade em educação do programa, os estudos recentes demonstram que a taxa de concluintes do ensino fundamental dentre os estudantes assistidos pelo BF é pouco menor que a dos demais alunos da escola pública $(75,6 \%$ contra $79,4 \%)$. Enquanto a taxa de abandono escolar é menor tanto nos anos iniciais (1,5\% contra $1,8 \%$ ), quanto nos finais $(4,4 \%$ contra $4,8 \%)$. Já taxa de aprovação é ligeiramente menor nos anos iniciais e finais (CRAVEIRO, XIMENES, 2013).

Entre os alunos do ensino médio assistidos pelo BF, a taxa de abandono é menor que entre os demais alunos da rede pública (7,4\% contra $11,3 \%)$; e a de aprovação maior (79,7\% contra $75,5 \%)$. No entanto, o resultado nacional de concluintes do ensino médio para jovens de 19 anos de idade é de apenas $49 \%$, sendo que entre os $20 \%$ mais pobres é de $29 \%$, quase três vezes menor que entre os $20 \%$ mais ricos, que é de $78 \%$ (10 anos do BF), reforçando a necessidade de maiores investimentos nessa etapa de ensino, principalmente com políticas voltadas ao público mais pobre (CRAVEIRO JCA, XIMENES DA, 2013).

Esses dados parecem indicar que, a progressão no ensino das crianças assistidas pelo BF é tão boa, se não melhor, que dos demais alunos das escolas públicas. Por sua vez, esse resultado parece estar diretamente ligado a garantia do acesso e da permanência do beneficiário ao serviço, e não meramente à ameaça de perder o benefício.

Desta forma, a condicionalidade em educação do PBF configura-se como uma estratégia fundamental para o desenvolvimento da cidadania das famílias mais pobres, na medida em que rompe, mesmo que de forma limitada, com a perpetuação geracional da exclusão escolar, garantindo-lhes o exercício do direito a educação. Ao mesmo tempo, revela que a oferta e a qualidade dos serviços sociais básicos, sobretudo a educação, às camadas mais pobres da população, ainda configura-se no grande desafio do Estado brasileiro. Uma vez que, ofertados os serviços e percebida sua qualidade, a população tende a buscar cada vez mais por eles.

Porém, o governo Jair Bolsonaro parece ter uma estratégia de desmonte dos direitos sociais, que implicam diretamente a educação e o Programa Bolsa Família. Como por exemplo, a Proposta de Emenda à Constituição (PEC) 186, de 2019, que além de tornar permanente o Teto de Gasto e estendê-lo aos Estados e Municípios, determina, de modo automático, a suspensão de aumento de despesa com pessoal e também o corte de alguns direitos dos servidores sempre que for descumprida a Regra de Ouro, que ocorre quando 
as operações de créditos superam os investimentos governamentais, e não apenas quando extrapolar o gasto com pessoal, fixado em lei complementar, ou quando os limites individuais de despesas por poderes e órgãos forem descumpridos (PEC, 186). Assim, este cenário pode comprometer a inserção dos mais pobres e, consequentemente, mais vulneráveis ao patamar de cidadania básico. O Programa Bolsa Família como uma estratégia de acesso a educação, que na avaliação da literatura, esta sendo importante para superação das desigualdades sociais, pode ser desmantelado e contribuir para dificultar o acesso à educação e, também, a construção da cidadania.

\section{CONSIDERAÇÕES FINAIS}

Tendo em vista os aspectos de vulnerabilidade da população mais pobre, que historicamente afastou geração após geração de crianças do direito a educação, o PBF, através das condicionalidades, constitui-se em uma relevante estratégia para o rompimento da transmissão intergeracional da pobreza e diminuição da desigualdade no Brasil. Cabe destacar, que o Brasil parece ainda carregar a herança histórica da colonização. A grande propriedade de terra, a precarização do trabalho (ou mesmo a escravidão funcional), e uma elite econômica sem sentimento de pertencimento nacional são ainda elementos que compõem a cultura política, econômica e social do país. Portanto, o papel interventor do Estado no equilíbrio das desigualdades e na promoção da cidadania é fundamental.

\section{REFERÊNCIAS}

1. ARBIX G. A queda Recente da Desigualdade no Brasil. Revista Brasileira de Ciências Sociais, São Paulo, junho de 2007; V. 22, n.6: 132-139.

2. BRASIL, 1934. In: CONSTITUIÇÃO da República dos Estados Unidos do Brasil: Diário Oficial da União.

3. BRASIL, 1946. In: CONSTITUIÇÃO dos Estados Unidos do Brasil; Diário Oficial da União.

4. BRASIL, 1988. In: CONSTITUIÇÃO da República Federativa do Brasil; Diário Oficial da União

5. BRASIL, 1996. In: LEI de Diretrizes e Bases da Educação Nacional; Diário Oficial da União.

6. CAMPELLO T, NERI MC (Org.) Programa Bolsa Família: uma década de inclusão e cidadania. Brasília: Ipea, 2013; $494 p$

7. CARVALHO JM. Cidadania no Brasil: O longo Caminho. Rio de Janeiro: Civilização Brasileira, 2014; 254p.

8. CRAVEIRO CBA, XIMENES DA. Dez anos do programa bolsa família: desafios e perspectivas para a universalização da educação básica no Brasil. In: CAMPELLO T, NERI MC (Org.) Programa Bolsa Família: uma década de inclusão e cidadania. Brasília: Ipea, 2013; 109-123.

9. CURY CRJ. A educação e a primeira constituinte republicana. In: FÁVERO O (org.). A educação nas constituintes brasileiras: 1823-1988. Campinas: Autores Associados, 1996; 69-80.

10. CURY CRJ. Sistema nacional de educação: desafio para uma educação igualitária e federativa. Campinas: Educação \& Sociedade, 2008; v. 29, n. 105: 1187-1209.

11. MARSHALL TH. Cidadania, Classe Social e Status. Rio de Janeiro: Zahar, 196; 220p.

12. MELCHIOR JCA. Financiamento da Educação: Subsídios à Constituinte. Porto Alegre: Revista de Financiamento da Educação, 2011; v.1, n.1;1-17.

13. MINISTÉRIO DA EDUCAÇÃO E CULTURA, 2016. In: FUNDEB.

14. NERI MC (Coord.). A Nova Classe Média: o lado brilhante dos pobres. Rio de Janeiro: FGV/CPS, 2010; 197p.

15. POCHMANN M. Política de educação: novos desafios no início do século XXI. In: SADER, Emir (Org.). O Brasil que queremos. Rio de Janeiro: UERJ, LPP, 2016; 139-155.

16. SAVIANI D et al. O legado educacional do século XX no Brasil. Campinas: Autores Associados, 2004; $203 p$.

17. SCHWARTZMAN S. A Educação em Ciências no Brasil. Rio de Janeiro: Instituto de Estudos do Trabalho e Sociedade, 2009; 209p.

18. SENADO, 2019. In: ATIVIDADE Legislativa. Proposta de Emenda à Constituição, número 186 de 2019.

19. SILVA MO, et al. A Política Social Brasileira no Século XXI: A prevalência dos programas de transferência de renda. São Paulo: Cortez, 2006; 223p. 